\title{
Preparation and Sound Insulation Performance of Superfine Metal Powder/Nitrile-Butadiene Rubber-Polyvinyl Chloride Microcellular Foaming Material
}

\author{
Sheng Hu $\mathbb{D},{ }^{1}$ Jun Cai $\mathbb{D},{ }^{2}$ Guofeng Liao, ${ }^{2}$ and Qiang Fu ${ }^{2}$ \\ ${ }^{1}$ State Grid Hunan Electric Power Company Limited Research Institute, Changsha, Hunan, China \\ ${ }^{2}$ School of Environmental Science and engineering, Shanghai Jiao Tong University, Shanghai 200240, China \\ Correspondence should be addressed to Jun Cai; juncai@sjtu.edu.cn
}

Received 29 July 2018; Revised 14 March 2019; Accepted 9 April 2019; Published 15 May 2019

Academic Editor: Minna Hakkarainen

Copyright (C) 2019 Sheng Hu et al. This is an open access article distributed under the Creative Commons Attribution License, which permits unrestricted use, distribution, and reproduction in any medium, provided the original work is properly cited.

\begin{abstract}
Lightweight sound insulation materials have received much attention. In this study, a series of superfine metal powder $(\mathrm{SFM})$ /nitrile-butadiene rubber (NBR)-polyvinyl chloride (PVC) microcellular foaming materials were prepared with NBR-PVC as matrix and SFM as modifiers by employing the method of molding foaming. Analysis on the morphology of cross section, pore size, and pore distribution possessed by SFM/NBR-PVC was conducted by scanning electron microscopy (SEM), as well as the image processing software of Image-Pro. Then detailed discussion on the effect of SFM with different mass fractions in the matrix on the foaming quality was provided. In the meanwhile, the performance of sound insulation was tested by four-channel impedance tube system. The results show significant improvement for foaming quality and sound insulation performance of NBR-PVC microcellular foaming material through the addition of SFM. In comparison with the pure NBR-PVC materials, the microcellular foaming material exhibits the best performance of foaming quality and sound insulation when the SFM content in matrix is $30 \mathrm{wt} \%$. It is shown that the average pore diameter and the foaming capacity decrease by $60 \%$ and $31 \%$, respectively, while the surface density increases by $131 \%$. In the meantime, the sound insulation index of SFM/NBR-PVC microcellular material increases by $7.2 \mathrm{~dB}$ to 30.5 $\mathrm{dB}$, which conforms to the requirements of new lightweight sound insulation materials in modern time. Finally, the mechanism of the optimization conducted for sound insulation performance after the addition of SMF is explained.
\end{abstract}

\section{Introduction}

It is widely acknowledged that the quiet and comfortable environment is a basic demand of human living, but the problem of noise pollution is getting increasingly worse along with the rapid development of modern industry [13]. The traditional devices adopted for soundproofing are mostly inorganic or metallic materials, which usually have shortcomings such as high density and poor performance of processing, limiting the widespread use [4-6]. Organic materials offer a precious opportunity for the development of light and soft sound insulation materials; however, homogeneous materials used for sound insulation follow the law of mass. Then, how to improve the performance of sound insulation shown by low-density organic materials is the key to its practicability, which as a result has attracted the attention of many researchers. At present, two main ways are available for improving the sound insulation performance of organic materials. The first way is known as filler modification. Wang $\mathrm{X}$ carried out relevant studies on the effect of Mica on the sound insulation properties of PVC composites [7]. Ahmadi $S$ discovered that inorganic nanosheet fillers, nanoclay, for instance, could result in the significant improvement of the sound insulation properties shown by composites [8]. Liang J analyzed the sound insulation behavior of inorganic particulate-filled polymer composites by means of acoustics theory in this article to reveal the mechanisms of sound insulation [9]. The second way is the employment of foaming. Teng Han designed a poly (vinyl chloride)-based composite material by alternating foam and membrane structure with the properties of good sound insulation [10]. Davoud J studied the processing, structural, and property relationships 
TABLE 1: Formulations of SFM/NBR-PVC microcellular foaming materials.

\begin{tabular}{|c|c|c|c|c|c|c|c|c|}
\hline No. & NBR & PVC & DOP & SFM & Stearic acid & $\mathrm{CZ}$ & Sublimed sulfur & $\mathrm{AC}$ \\
\hline $1 \#$ & 70 & 30 & 30 & 0 & 1.5 & 1.4 & 2 & 10 \\
\hline $2 \#$ & 70 & 30 & 30 & 10 & 1.5 & 1.4 & 2 & 10 \\
\hline 3\# & 70 & 30 & 30 & 20 & 1.5 & 1.4 & 2 & 10 \\
\hline $4 \#$ & 70 & 30 & 30 & 30 & 1.5 & 1.4 & 2 & 10 \\
\hline $5 \#$ & 70 & 30 & 30 & 40 & 1.5 & 1.4 & 2 & 10 \\
\hline
\end{tabular}

needed for highly expanded open-cell polycarbonate (PC) foams, and acoustic insulation, thermal conductivity, and mechanical properties of the foams were characterized [11].

The introduction of organic particles will lead to the heavier weight of polymer consequently. However, the polymer microcellular foaming material exhibits advantages in the aspects of low density and excellent processing performance $[12,13]$, as well as special porous structure, which can lead to the complicated propagation direction of the acoustic wave, prolong the path of propagation, and then reduce the strength of acoustic wave effectively. On the basis of excellent properties, the polymer microcellular foaming materials show great potential in the field of noise reduction [14-16]. At present, it is quite difficult for the sound insulation performance reflected by the traditional microcellular foaming material to satisfy the demands of practical applications because of the large pore size and distribution of wide pore. It is indicated by many reports that additives with microsize in the polymer materials, as the small-size effect, can improve the foaming quality (pore size, pore distribution, foaming capacity, etc.) significantly [17].

Nitrile-butadiene rubber/polyvinyl chloride (NBR/PVC) materials with outstanding integrated properties, such as cross-linked rubber elasticity and oil resistance derived from NBR, as well as the plasticity, weather resistance, and chemical corrosion shown by PVC, are expected to have brilliant application prospect $[18,19]$. In this paper, a series of SFM/NBR-PVC composites were prepared, with NBR-PVC as the matrix and superfine metal powder (SFM) as additive. Then a detailed discussion was presented on the influence of the mass fraction of SFM on the micromorphology, foaming quality, and sound insulation performance. Finally, the mechanism adopted by the optimization of sound insulation performance after the addition of SMF was explained.

\section{Experimental}

2.1. Materials. (1) Polyvinyl chloride (PVC): White powder with a polymerization degree of $1000 \pm 150$ and a density of 1.4 $\mathrm{g} \cdot \mathrm{cm}^{-3}$ was purchased from Shanghai Chlor-Alkali Chemical Co., Ltd.

(2) Nitrile-Butadiene Rubber (NBR): The structural formula is shown in Figure 1. The brown-yellow solid with an acrylonitrile content of $33 \%$ and a density of $1 \mathrm{~g} \cdot \mathrm{cm}^{-3}$ was purchased from Ningbo Dehe Rubber Co., Ltd.

(3) Dioctyl phthalate (DOP): Transparent viscous liquid with molecular formula $\mathrm{C}_{24} \mathrm{H}_{38} \mathrm{O}_{4}$ was purchased from Dongying Vejen Chemical Co., Ltd. Its function is primary plasticizer.

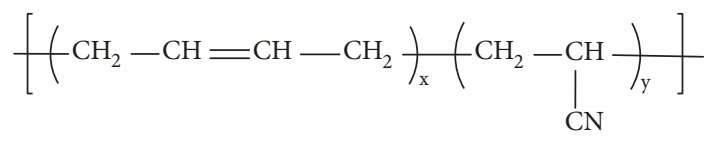

FIGURE 1: Molecular structural formula of NBR.

(4) Stearic acid, CZ accelerator, and sublimed sulfur (S) were all of industrial grade. Their functions are separately mold-release agent, sulfur vulcanization accelerator, and rubber vulcanization.

(5) Superfine metal powder (SFM): Gray powder with the micron-size particle and density of $7.16 \mathrm{~g} \cdot \mathrm{cm}^{-3}$ was purchased from Ganzhou Tianliao Nonferrous Metal Co., Ltd.

2.2. Preparation of Test Sample. In order to evaluate the influence of SFM on the sound insulation properties of NBR-PVC microfoaming materials, NBR-PVC with a rubber-plastic ratio of 70:30 was selected as the matrix, and the microfoaming material was prepared by the method of mold foaming. Table 1 shows the formulations of the samples. The sample preparation process can be divided into prevulcanization treatment, vulcanization treatment, and postvulcanization treatment.

Prevulcanization treatment: Firstly, PVC, SFM, etc. were put into the vacuum drying oven for $4 \mathrm{~h}$ (temperature $60^{\circ} \mathrm{C}$ ). Secondly, NBR, PVC, DOP, and stearic acid were weighed according to the mass ratio listed in Table 1 and then kneaded for $2 \mathrm{~min}$ in an open mixing mill (temperature of $160^{\circ} \mathrm{C}$ and speed of $20 \mathrm{r} \cdot \mathrm{min}^{-1}$ shown in Figure 2(a)). Then, a modifier (SFM) was added and kneaded for 5 minutes. After being cooled to room temperature, sublimation sulfur, CZ accelerator, and $\mathrm{AC}$ foaming agent were added to the open mixing mill (temperature $60 \mathrm{C}$, speed $20 \mathrm{R} \mathrm{min}-1$ ) according to the corresponding proportion, kneading for 5 minutes.

Vulcanization and chemical foaming treatment: The blend was kept at room temperature for $24 \mathrm{~h}$, and then it was kneaded for 5 minutes in the open mixing mill (with the speed of $20 \mathrm{r} \cdot \mathrm{min}^{-1}$ at room temperature). Then the blend was molded and chemically foamed on the vulcanizing press (with the temperature of $160^{\circ} \mathrm{C}$ and the pressure of $10 \mathrm{MPa}$ shown in Figure 2(b)) for 15 minutes.

Posttreatment: The blend was take out after cooling down for 24 hours at room temperature. Finally, the blend obtained was cut into the proper sample according to requirement for testing.

2.3. Characterization and Testing. The bubble structure of microfoaming was observed by JSM7600F field emission 


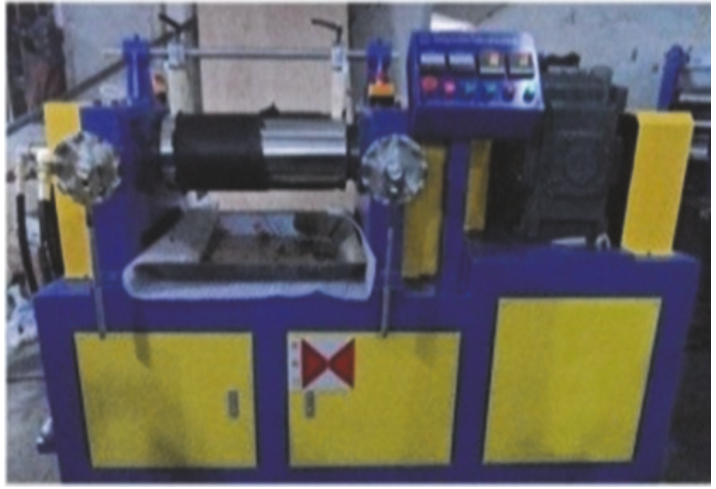

(a)

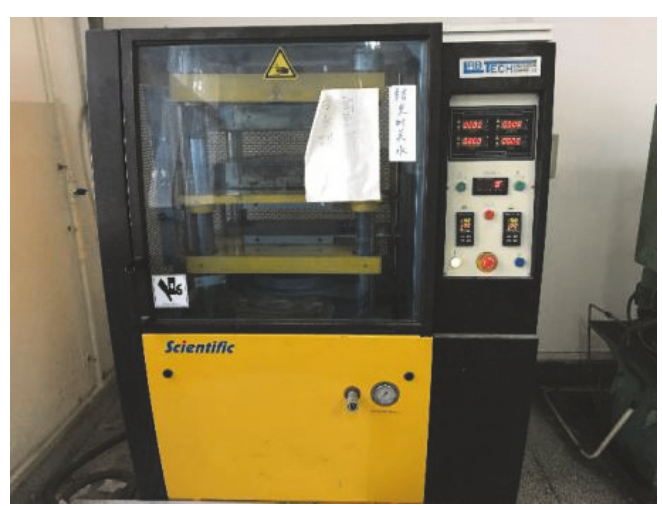

(b)

FIgURE 2: The material preparation devices: (a) open mixing mill, (b) vulcanizing press device.

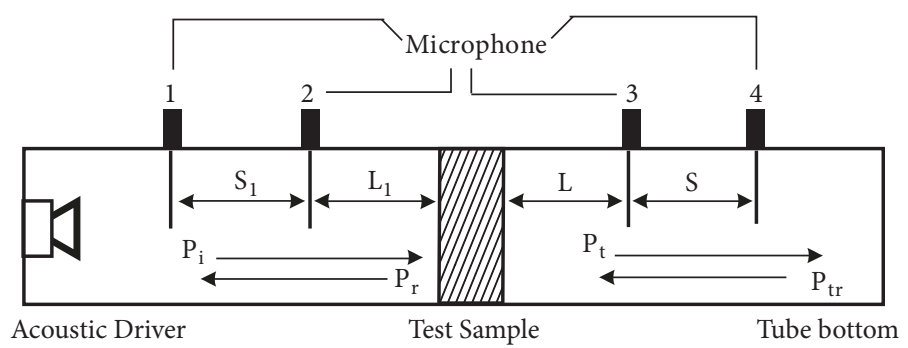

FIgURE 3: Impedance tube schematic.

scanning electron microscopy (FE-SEM) produced by JEOL. After that, the SEM sample was imported into the image processing software of Image-Pro, the bubble size was processed statistically, and then the quantity of bubbles in each sample was counted as no less than 100. Afterwards, the apparent density of foaming material was measured based on the method stated in GB/T 6343-2009. Then, the foaming capacity $V_{f}$ and average pore size $\bar{D}$ of microfoaming materials were calculated by employing formula (1) and formula (2), respectively.

$$
V_{f}=\left(1-\frac{\rho_{f}}{\rho}\right) \times 100 \%
$$

where $V_{f}$ refers to the foaming capacity of foaming sample; $\rho_{f}$ indicates the density of foaming sample; and $\rho$ denotes the density of solid sample.

$$
\bar{D}=\frac{1}{n} \sum_{i}^{n} D_{i}
$$

where $\bar{D}$ refers to the average diameter of foaming material; $n$ indicates the bubble number of foaming material; $i$ denotes the $i$-th bubble; and $D_{i}$ represents the diameter of the $i$-th bubble.

The distribution of pore size refers to the percentage of pore size calculated according to the quantity or volume at different levels of pore sizes in materials. In this paper, the distribution of pore size is calculated based on the quantity of pore sizes at different levels.
Surface density refers to the mass obtained per unit area $\left(\mathrm{g} \cdot \mathrm{cm}^{-2}\right)$. The surface density is calculated by the parameters of bulk density and thickness of material.

The four-channel impedance tube acoustic analyzer produced by BSWA Technology Co., Ltd. (BSSFMA), was employed for testing the performance shown by sound insulation of the sample according to GB/Z 27764-2011, which is shown in Figure 3. The sizes of the samples are listed as follows: the diameter of the tube is $100 \mathrm{~mm}$ and the diameter of the small tube is $29 \mathrm{~mm}$. The range of the frequency measured is $80-6300 \mathrm{~Hz}$ (the frequency range of $80-4000 \mathrm{~Hz}$ is selected for analysis in this paper for the purpose of ensuring the reliability of the experimental data). Besides, analysis on the data obtained from the experiment is conducted by using VA-Lab 4 software. At least a total of 5 samples are measured in each group, and finally the test results are averaged.

\section{Results and Discussion}

3.1. The Effect of SFM on Morphology Quality. Figure 4 shows the SEM images obtained from the SFM/NBR-PVC microcellular foaming material and SFM powder. It is shown in Figure 4(a) that the pore size is unevenly distributed in pure NBR-PVC microcellular foaming materials, and it is also observed that a lot of pores collapse and merge in some regions. After SFM modification, the pore structure experiences obvious changes. When the content of SFM is 10 $\mathrm{wt} \%$, the regions where there were collapse and merging of 


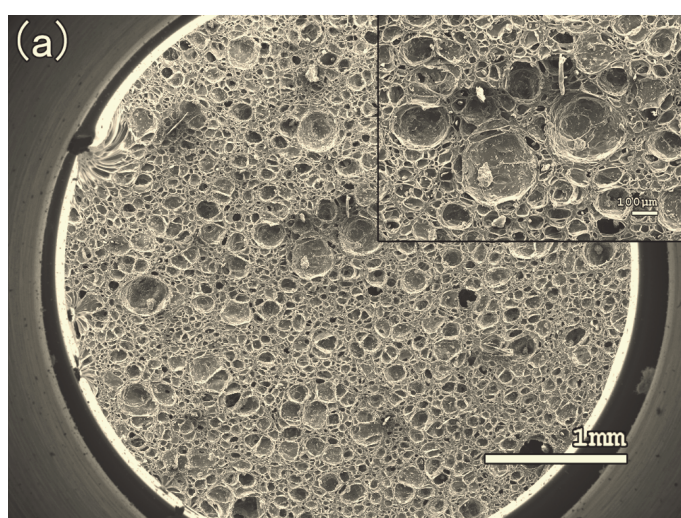

(a)

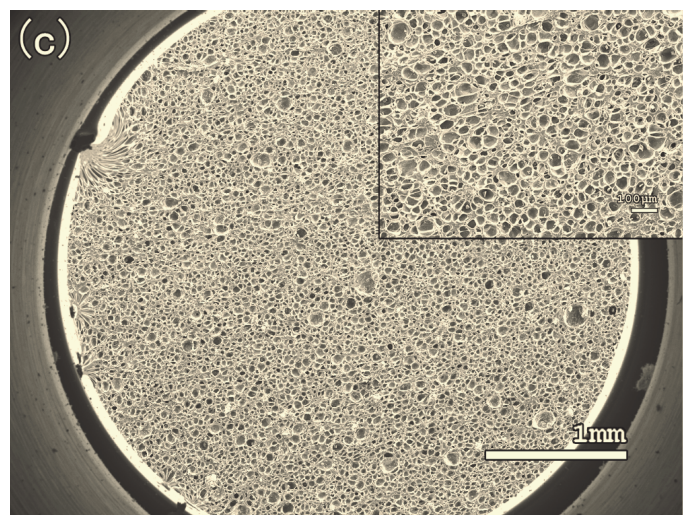

(c)

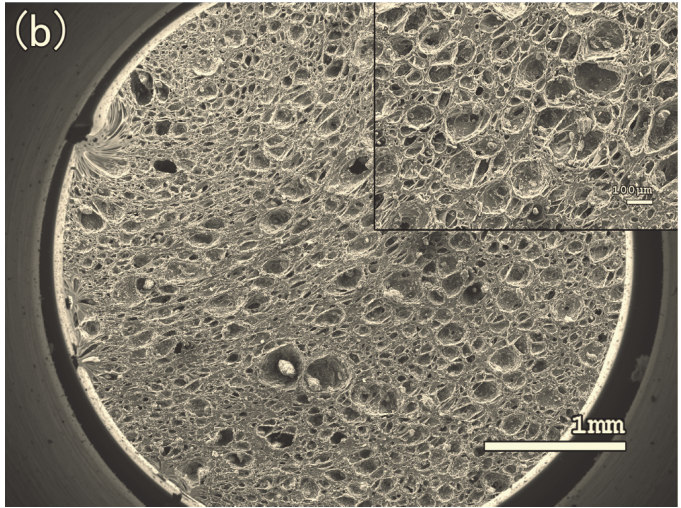

(b)

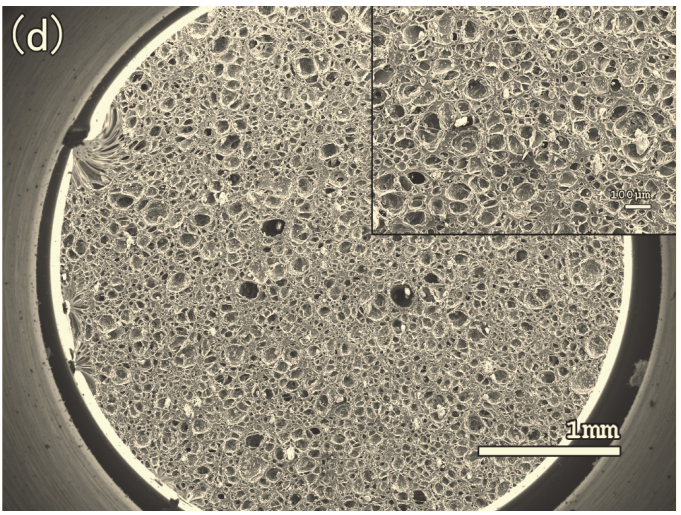

(d)

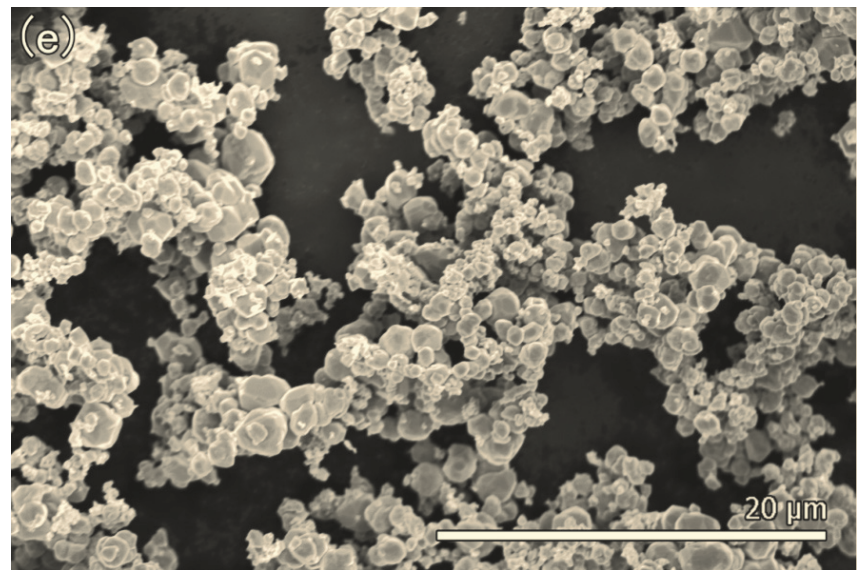

(e)

FIGURE 4: SEM images of fractured surface of SFM/NBR-PVC materials and SFM: (a) 0 wt\%, (b) 10 wt\%, (c) 30 wt $\%$, (d) 40 wt\%, (e) SFM.

pores are improved greatly, and orientation is manifested, which could be ascribed to the heterogeneous nucleation causeddirectly by SFM additives. When SFM is added to the NBR-PVC matrix, the potential energy facilitating the nucleation of the pores could increase significantly, which as a result can promote the nucleation of the pores and then reduce the regions where there were collapse and merging of pores. When the content of SFM is insufficient, only a part of the pores can be created because of heterogeneous nucleation, which may consequently lead to the orientation of pores in certain region because of the uneven stress throughout the materials. When the SFM content is not enough, only part of pores is formed via heterogeneous nucleation, and it may result in pore orientation in the material under the influence of uneven stress. When the content of SFM increases to 30 wt $\%$, no region would be identified with the phenomenon of pore collapse and merging. Actually, this result can be explained by the fact that the content of SFM can just ensure 
TABLE 2: Surface density, average diameter, and foaming capacity of SFM/NBR-PVC microcellular foaming materials.

\begin{tabular}{lcccc}
\hline $\begin{array}{l}\text { Content of SFM } \\
(\mathrm{wt} \%)\end{array}$ & $\begin{array}{c}\text { Thickness } \\
(\mathrm{cm})\end{array}$ & $\begin{array}{c}\text { Surface density } \\
\left(\mathrm{g} \cdot \mathrm{cm}^{-2}\right)\end{array}$ & $\begin{array}{c}\text { Average diameter } \\
\pm \text { Standard } \\
\text { deviation }(\mathrm{um})\end{array}$ & $\begin{array}{c}\text { foaming capacity } \\
(\%)\end{array}$ \\
\hline 0 & 0.6 & 0.156 & $70.35 \pm 19.51$ & 76.5 \\
10 & 0.6 & 0.228 & $64.03 \pm 17.14$ & 73.6 \\
20 & 0.6 & 0.276 & $48.75 \pm 12.19$ & 61.7 \\
30 & 0.6 & 0.360 & $28.10 \pm 5.23$ & 52.8 \\
40 & 0.6 & 0.336 & $41.59 \pm 7.47$ & 62.7 \\
\hline
\end{tabular}

that the pores are formed via heterogeneous nucleation, and the disappearance of pore orientation can be seen as well in Figure $4(\mathrm{c})$. When the content of SFM is further increased to $40 \mathrm{wt} \%$, the phenomenon of pore collapse and merging comes into existence again (Figure $4(\mathrm{~d})$ ), which is mainly caused by the excessive content of SFM and the tendency of agglomeration in the fine metal particles.

3.2. The Effect of SFM on Foaming Quality. It is obtained that the foaming quality can be reflected by some parameters such as pore distribution, average pore diameter, surface density, and foaming ratio. Table 2 shows the surface density, average pore diameter, and foaming ratio of the as-prepared foaming materials with different contents of SFM. Analysis on the pore size is carried out using the Image-Pro image processing software on the basis of SEM images, and the distribution of pores is displayed in Figure 5. On the whole, in comparison with the pure NBR-PVC material, as-prepared SFM/NBRPVC materials have a smaller pore size and a narrower pore distribution. When the SFM content is $10 \mathrm{wt} \%$, the pore size tends to be smaller, but the pore distribution is still relatively wide. When the SFM is $30 \mathrm{wt} \%$, the foaming material shows the narrowest pore distribution with the value at the peak of $30 \mu \mathrm{m}$, and the pore size changes to be obviously smaller. Moreover, when the SFM content is further increased to 40 $\mathrm{wt} \%$, oppositely, the pore size tends to be larger and the pore distribution tends to be wider in comparison with these of the as-prepared foaming material which contains $30 \mathrm{wt} \%$ SFM. As shown in Table 2, it can be obviously seen that the surface density of SFM/NBR-PVC materials shows a tendency of increasing first and then decreasing with the increase of SFM content, but the corresponding foaming capacity shows an opposite trend. However, when the SFM content is 30 $\mathrm{wt} \%$, the SFM/NBR-PVC material shows the highest surface density, $0.360 \mathrm{~g} \cdot \mathrm{cm}^{-2}$. In comparison with the pure NBRPVC material, the surface density increases by $131 \%$, and the foaming capacity is $60 \%$ of that of the pure NBR-PVC material. It is quite obvious that the foaming quality of NBRPVC material improves significantly after the introduction of SFM modifier, and the foaming quality shows the best performance when the percentage of SFM is $30 \mathrm{wt} \%$ in the matrix.

3.3. The Sound Insulation Performance of SFM/NBR-PVC Materials. Figure 6 shows the sound insulation performance spectrum (Figure 6(a)) and sound insulation index of both as-prepared NBR-PVC and SFM/NBR-PVC materials. It can be observed that the changing trends of sound insulation along with frequency are the same for all foaming materials, as shown in Figure 6(a). Moreover, the performance of sound insulation during all the testing frequencies increases significantly after the modification of SFM. Figure 6(b) exhibits the sound insulation index of each sample. In addition, the sound insulation index is improved as well. In terms of the pure NBR-PVC material, the sound insulation index obtained is $23.3 \mathrm{~dB}$. After that, the sound insulation index is improved by $3.6 \mathrm{~dB}, 5.4 \mathrm{~dB}, 7.2 \mathrm{~dB}$, and $6.2 \mathrm{~dB}$, respectively, when the content of SFM in the matrix is $10 \mathrm{wt} \%, 20 \mathrm{wt} \%, 30 \mathrm{wt} \%$, and $40 \mathrm{wt} \%$. It is indicated by these results that the performance of sound insulation is improved obviously because of the addition of SFM modifier, and the optimal content gained is $30 \mathrm{wt} \%$.

3.4. Analysis on the Sound Insulation Mechanism of SFM/ NBR-PVC Microfoaming Material. The sound insulation mechanism of microcellular foaming materials is much more complicated than that of traditional solid sheet. Figures 7(a) and 7(b) show the mechanism reflected by the sound insulation of pure NBR-PVC material and SFM/NBR-PVC material, respectively.

After the employment of SFM modifier, the performance of sound insulation shown by NBR-PVC microcellular material is improved significantly, which may be caused by the more complex mechanism of sound insulation for SFM/NBR-PVC materials. Firstly, the pore size obtained becomes smaller and the number of pores decreases after the addition of SFM, and the number of pore/air interfaces increases as well, which as a result can improve the amount of reflection and scattering of acoustic waves [20]. Moreover, the propagation route of acoustic waves in SFM/NBR-PVC tends to be complicated and the propagation path is lengthened as well, which thereby increases the attenuation of acoustic wave. More than that, the SFM modifier also introduces SFM and NBR-PVC interfaces in large amount, and it enhances the reflection of acoustic waves due to the mismatch of the acoustic impedance for the two materials. Finally, the addition of SFM modifier helps increase the surface density of NBR-PVC microcellular foaming materials as well, which benefits the improvement of the sound insulation performance during the ranges of middle and high frequencies when it is influenced by the law of mass action.

On the basis of the above-mentioned analysis, the NBRPVC material modified by SFM shows better performance of sound insulation, which can be attributed to the synergistic 


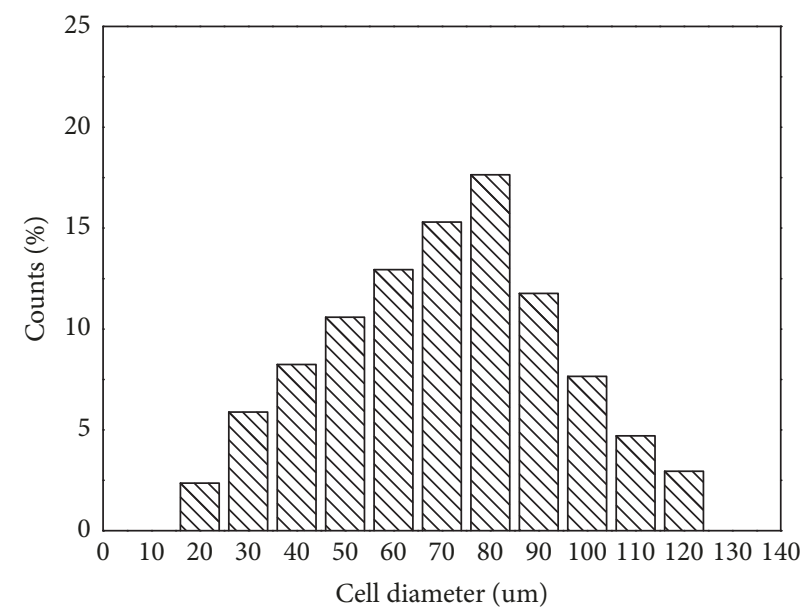

(a)

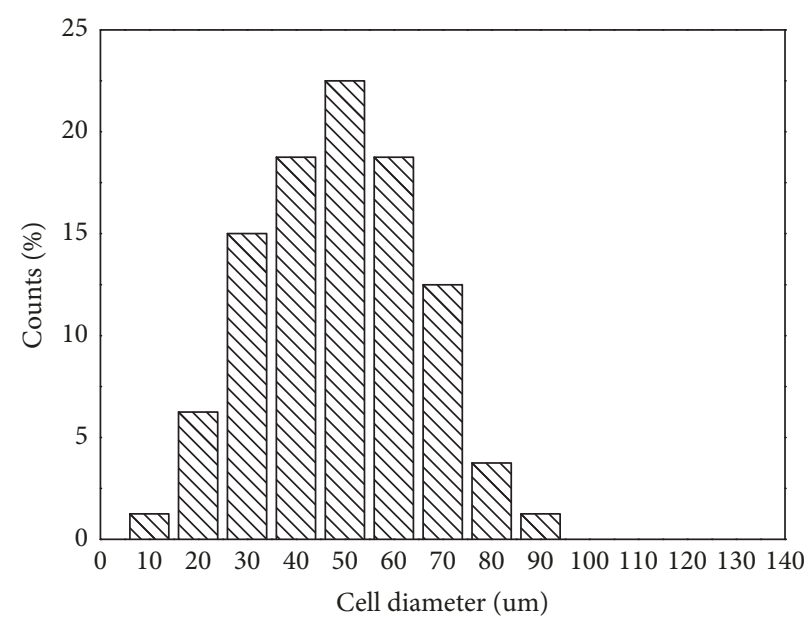

(c)

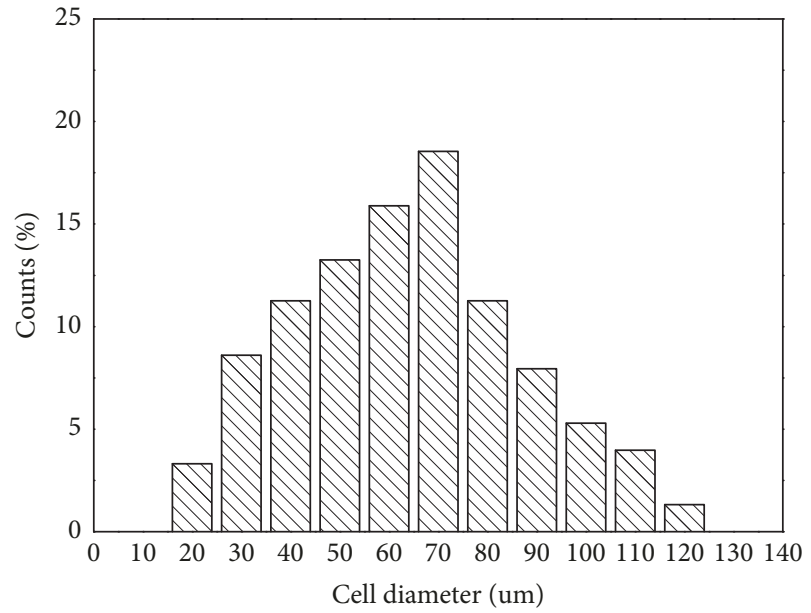

(b)

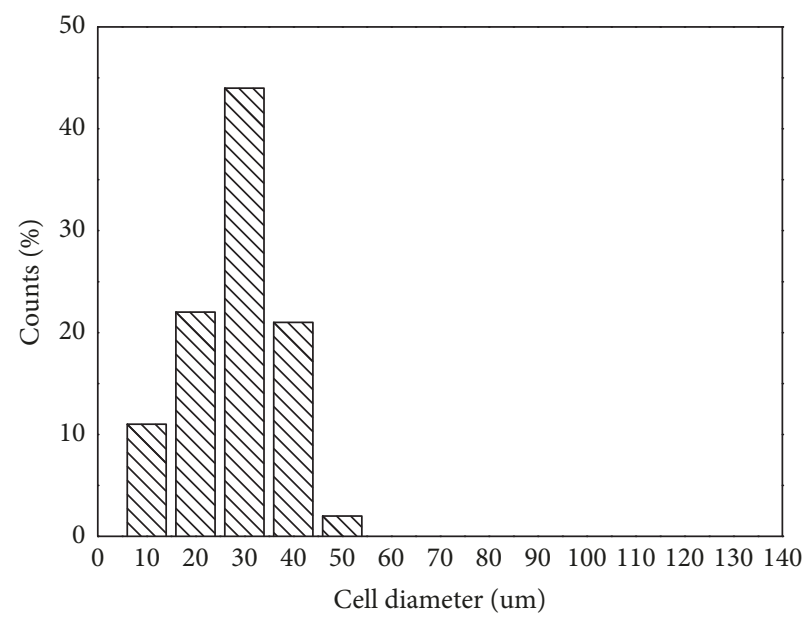

(d)

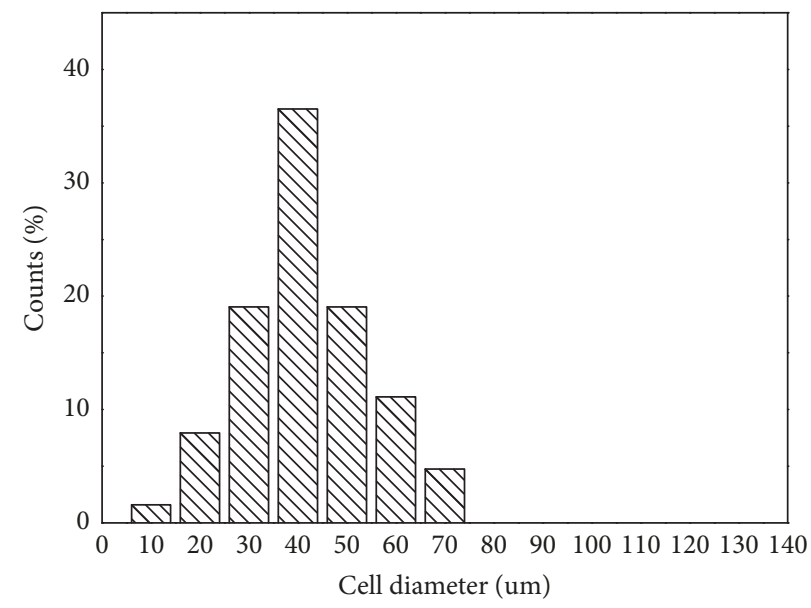

(e)

Figure 5: Pore diameter distribution of SFM/NBR-PVC microcellular foaming materials: (a) 0wt\%, (b) $10 \mathrm{wt} \%$, (c) $20 \mathrm{wt} \%$, (d) $30 \mathrm{wt} \%$, (e) 40wt\%. 

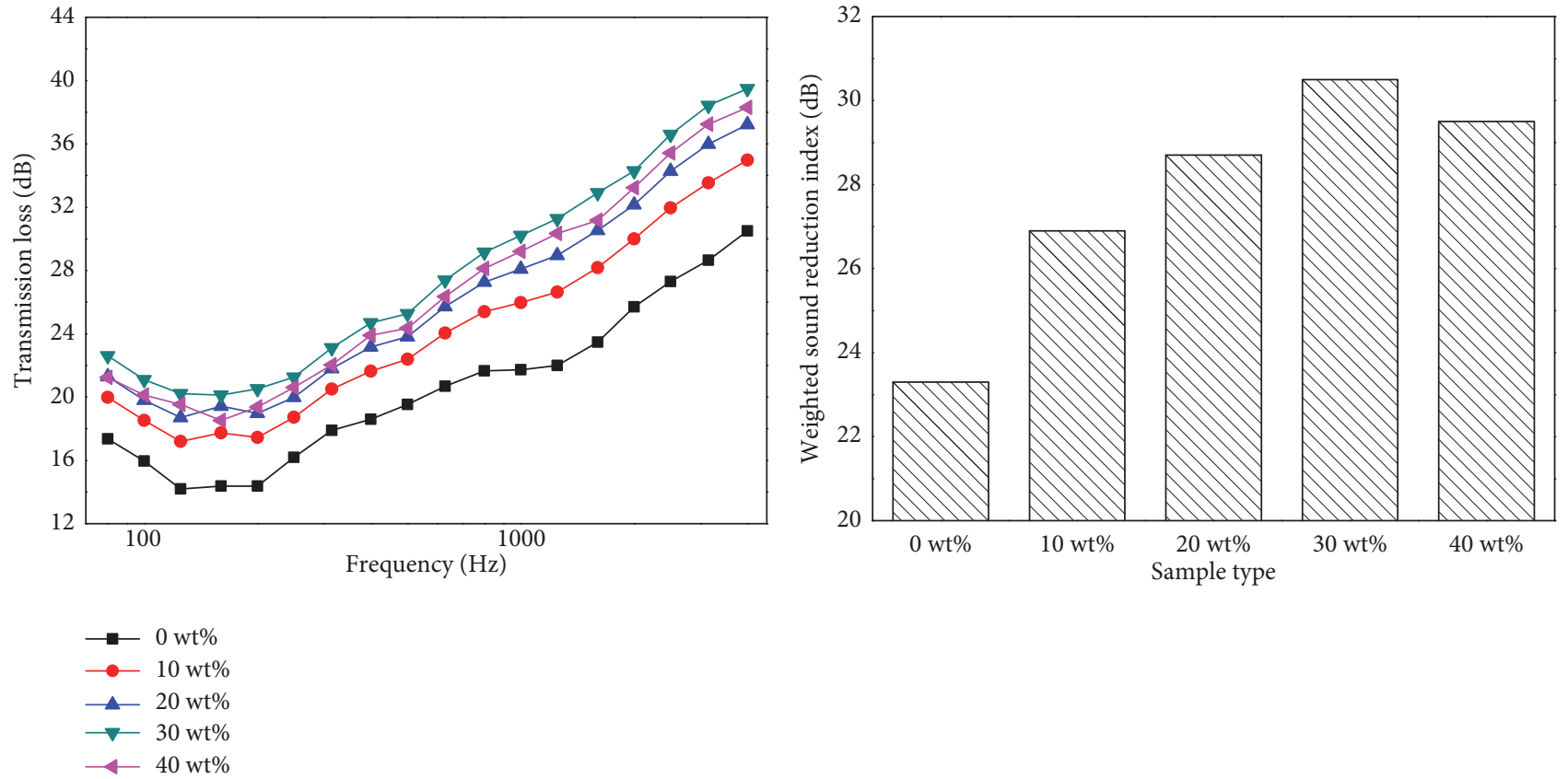

(a)

(b)

FIGURE 6: Sound insulation property of SFM/NBR-PVC microcellular foaming materials: (a) spectrum graph, (b) weighted sound insulation index histogram.

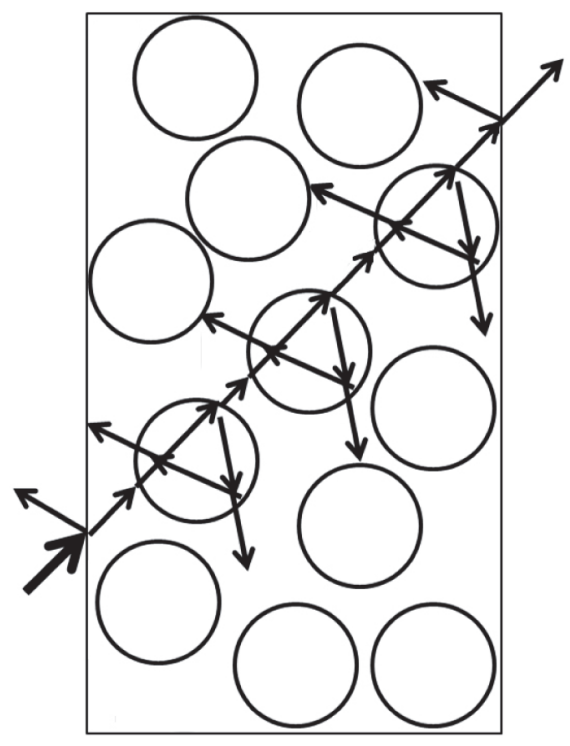

(a)

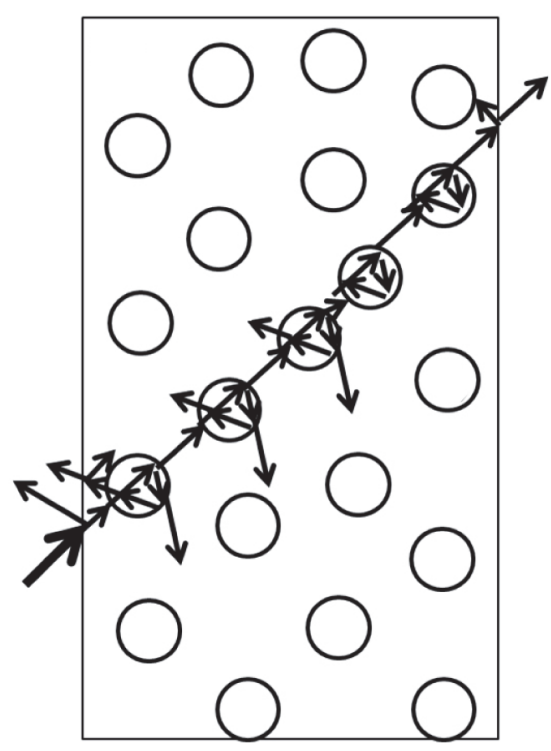

(b)

FIGURE 7: Acoustic principle diagram of foam material: (a) NBR-PVC, (b) SFM/NBR-PVC.

effect of various factors such as the distribution of cell size, impedance mismatch region, and material surface density.

In this paper, when the SFM content is $30 \mathrm{wt} \%$, it is observed that the as-prepared SFM/NBR-PVC microcellular foaming material exhibits the best performance of sound insulation, and the index of sound insulation obtained reaches $30.5 \mathrm{~dB}$, which is mainly caused by the fact that this material has the largest area of impedance mismatch, the narrowest pore distribution, and the largest surface density. When acoustic waves pass through the material, this results in the maximum amount of acoustic energy reflection, the minimum resonance, and the maximum sound insulation in the range of middle and high frequencies. 


\section{Conclusion}

In this paper, lightweight SFM/NBR-PVC microcellular foaming materials with good performance of sound insulation were prepared by employing the method of mold foaming, and NBR-PVC was used as the matrix while SFM was employed as modifier. Then the detailed discussion was given on the influence imposed by the content of SFM modifier in the matrix on the morphology and performance of sound insulation. The results demonstrate the following:

(1) The results obtained from morphology characterization show that SFM modification can significantly enhance the foaming quality of NBR-PVC microcellular foaming materials. In addition, when the content of SFM is $30 \mathrm{wt} \%$, the microcellular foaming material shows that the narrowest pore distribution is obtained at the peak of $30 \mu \mathrm{m}$; the average pore size and foaming capacity decrease by $60 \%$ and $31 \%$, respectively; and the surface density increases by $131 \%$.

(2) Performance of sound insulation obtained from testing results shows that the addition of SFM modifier obviously improves the performance of sound insulation shown by microcellular foaming materials. When the SFM mass fraction is $30 \%$, this material shows the best performance of sound insulation.

(3) In comparison with pure NBR-PVC materials, the index of sound insulation increases by $7.2 \mathrm{~dB}$, reaching to $30.5 \mathrm{~dB}$, which conforms well to the requirements of new lightweight sound insulation materials in modern time.

\section{Data Availability}

The data used to support the findings of this study are available from the corresponding author upon request.

\section{Conflicts of Interest}

The authors declare that they have no conflicts of interest.

\section{References}

[1] M. Alayrac, C. Marquis-Favre, and S. Viollon, "Total annoyance from an industrial noise source with a main spectral component combined with a background noise," The Journal of the Acoustical Society of America, vol. 130, no. 1, pp. 189-199, 2011.

[2] A. M. Dzhambov and D. D. Dimitrova, "Residential road traffic noise as a risk factor for hypertension in adults: Systematic review and meta-analysis of analytic studies published in the period 2011-2017," Environmental Pollution, vol. 240, pp. 306318, 2018.

[3] G. S. Ramsis, B. S. Mats, S. Thomas et al., "Development of ultralow-noise transformer technology," Environmental Pollution, vol. 240, pp. 306-318, 2018.

[4] J. Cai, Q. Fu, M. Long, G. Liao, and Z. Xu, “The sound insulation property of composite from waste printed circuit board and unsaturated polyester," Composites Science and Technology, vol. 145, pp. 132-137, 2017.

[5] Y. Xiao, J. Wen, and X. Wen, "Sound transmission loss of metamaterial-based thin plates with multiple subwavelength arrays of attached resonators," Journal of Sound and Vibration, vol. 331, no. 25, pp. 5408-5423, 2012.
[6] C. F. Ng and C. K. Hui, "Low frequency sound insulation using stiffness control with honeycomb panels," Applied Acoustics, vol. 69, no. 4, pp. 293-301, 2008.

[7] X. Wang, F. You, F. S. Zhang, J. Li, and S. Guo, "Experimental and theoretic studies on sound transmission loss of laminated mica-filled poly(vinyl chloride) composites," Journal of Applied Polymer Science, vol. 122, no. 2, pp. 1427-1433, 2011.

[8] S. Ahmadi, P. Nassiri, I. Ghasemi, and M. R. M. Esmaeilpoor, "Sound transmission loss through nanoclay-reinforced polymers," Iranian Polymer Journal (English Edition), vol. 24, no. 8, pp. 641-649, 2015.

[9] J.-Z. Liang and X.-H. Jiang, "Sound insulation in polymer/ inorganic particle composites. I. Theoretical model," Journal of Applied Polymer Science, vol. 125, no. 1, pp. 676-681, 2012.

[10] T. Han, X. Wang, Y. Xiong, J. Li, S. Guo, and G. Chen, "Lightweight poly(vinyl chloride)-based soundproofing composites with foam/film alternating multilayered structure," Composites Part A: Applied Science and Manufacturing, vol. 78, pp. 27-34, 2015.

[11] D. Jahani, A. Ameli, M. Saniei, W. Ding, C. B. Park, and H. E. Naguib, "Characterization of the structure, acoustic property, thermal conductivity, and mechanical property of highly expanded open-cell polycarbonate foams," Macromolecular Materials and Engineering, vol. 300, no. 1, pp. 48-56, 2015.

[12] M.-S. Kim, J. Yan, K.-M. Kang et al., "Soundproofing properties of polypropylene/clay/carbon nanotube nanocomposites," Journal of Applied Polymer Science, vol. 130, no. 1, pp. 504-509, 2013.

[13] S. Li, Y. Wang, J. Ding, H. Wu, and Y. Fu, "Effect of shear thickening fluid on the acoustic insulation property of textiles," Textile Research Journal, vol. 84, no. 9, pp. 897-902, 2013.

[14] T.-C. Hung, J.-S. Huang, Y.-W. Wang, and K.-Y. Lin, "Inorganic polymeric foam as a sound absorbing and insulating material," Construction and Building Materials, vol. 50, pp. 328-334, 2014.

[15] J.-O. Yeon, K.-W. Kim, K.-S. Yang, J.-M. Kim, and M.-J. Kim, "Physical properties of cellulose sound absorbers produced using recycled paper," Construction and Building Materials, vol. 70, pp. 494-500, 2014.

[16] C. Zhang, J. Li, Z. Hu, F. Zhu, and Y. Huang, "Correlation between the acoustic and porous cell morphology of polyurethane foam: effect of interconnected porosity," Materials \& Design, vol. 41, pp. 319-325, 2012.

[17] J. Yan, S. M. Kim, M. K. Kang et al., "Evaluation of PP/clay composites as soundproofing material," Polymers Polymer Composites, vol. 22, pp. 65-72, 2014.

[18] H. Li, L. Wang, G. Song et al., "Study of NBR/PVC/OMMT nanocomposites prepared by mechanical blending," Iranian Polymer Journal (English Edition), vol. 19, no. 1, pp. 39-46, 2010.

[19] X. Huang, N. Tian, T. Wang, K. Wang, and Q. Xue, "Friction and wear properties of NBR/PVC composites," Journal of Applied Polymer Science, vol. 106, no. 4, pp. 2565-2570, 2007.

[20] P. C. Pedersen, O. Tretiak, P. He et al., "Impedance-matching properties of an inhomogeneous matching layer with continuously changing acoustic impedance," The Journal of the Acoustical Society of America, vol. 72, no. 2, pp. 327-336, 1982. 


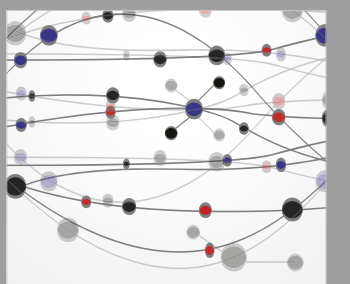

The Scientific World Journal
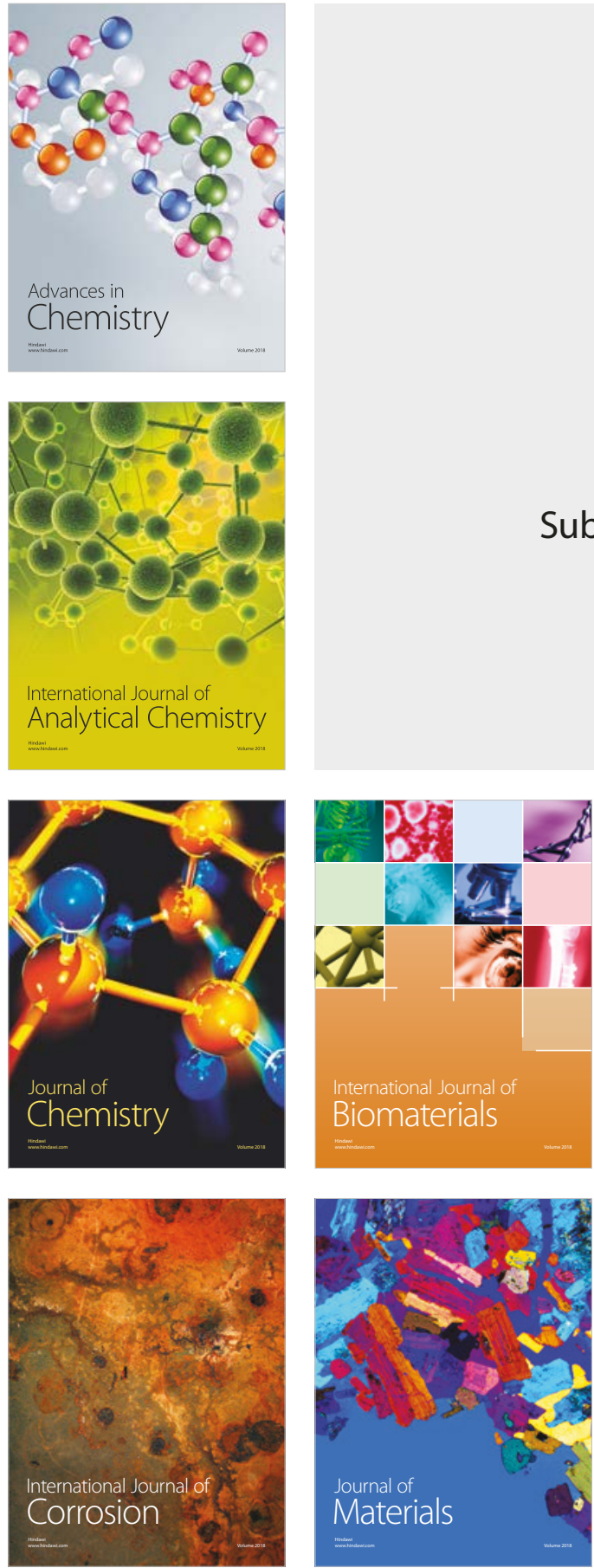

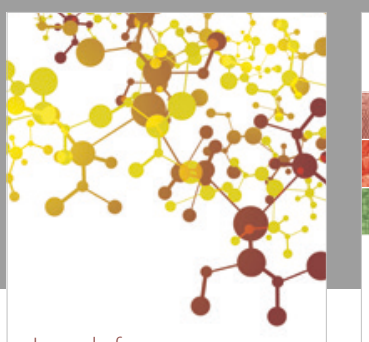

Journal of

Applied Chemistry
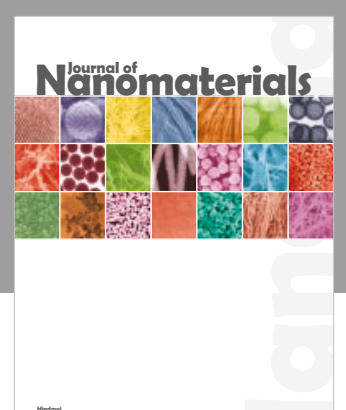

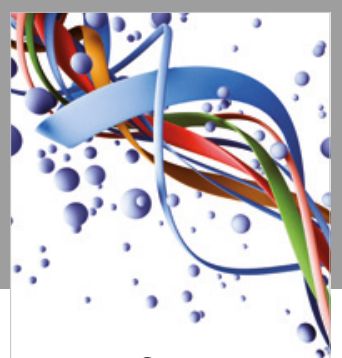

Scientifica

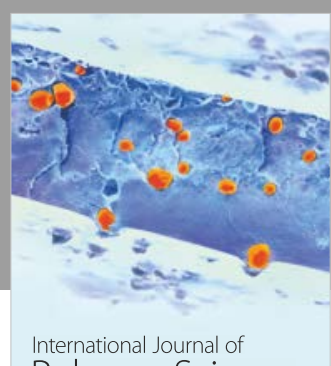

Polymer Science

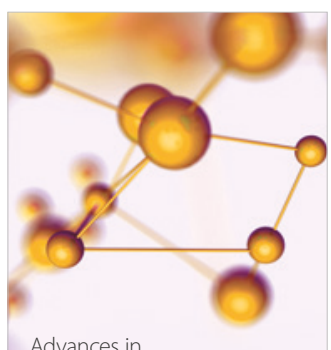

Physical Chemistry
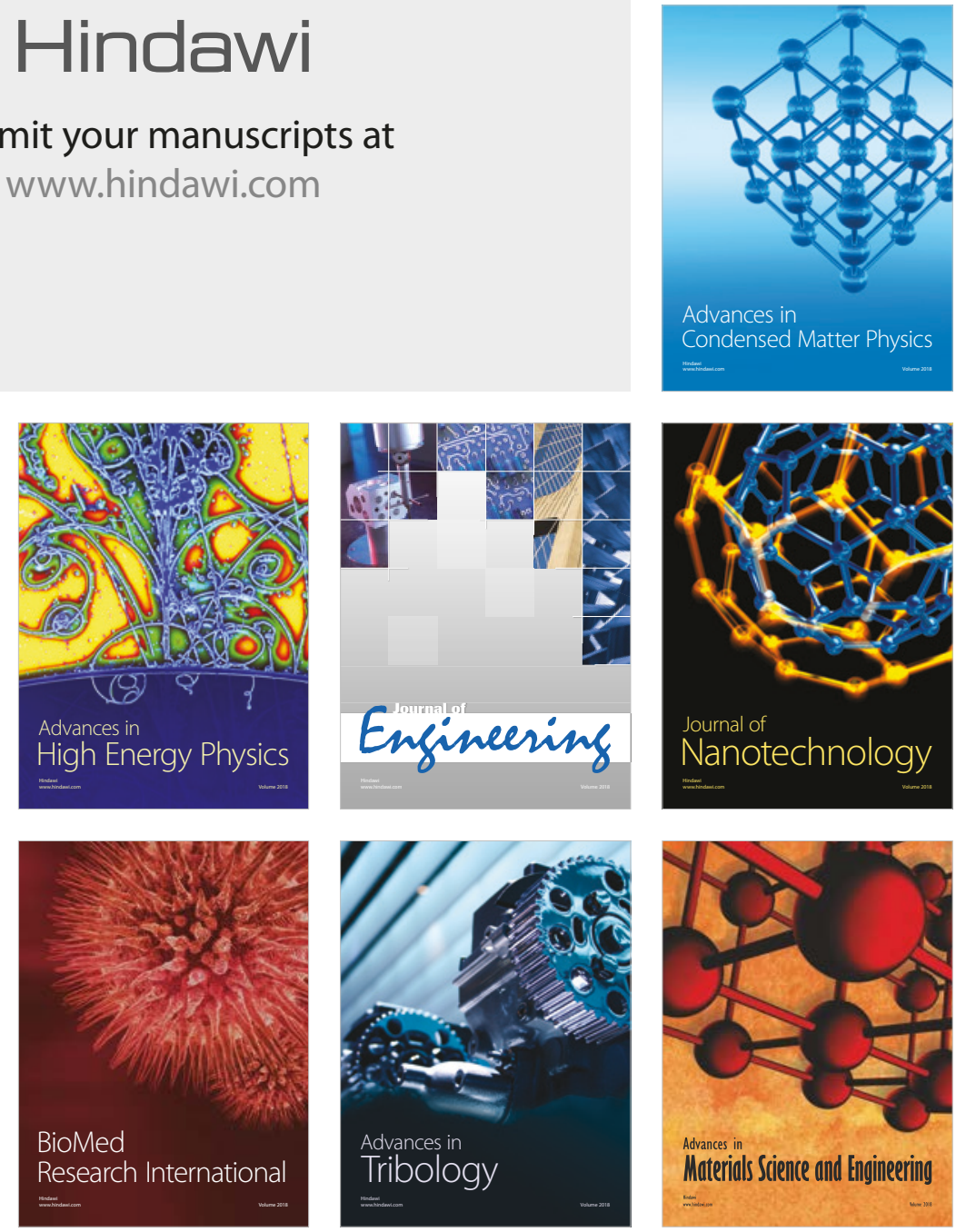